\title{
The protective role of Professional Self-Concept and Job Embeddedness on Nurses' Burnout: Structural Equation Modeling
}

soghra goliroshan

Semnan University of Medical Sciences and Health Services

Monir Nobahar ( $\square$ nobahar43@semums.ac.ir)

Nayyereh Raeisdana

Semnan University of Medical Sciences and Health Services

zahra ebadinejad

Semnan University of Medical Sciences and Health Services

parvin Aziznejadroshan

Babol University of Medical Science Faculty of Nursing and Midwifery

Research article

Keywords: Professional Self-concept, Job embeddedness, Burnout, Nurse

Posted Date: June 17th, 2020

DOl: https://doi.org/10.21203/rs.3.rs-33663/v1

License: (1) (i) This work is licensed under a Creative Commons Attribution 4.0 International License.

Read Full License 


\section{Title page}

\section{The protective role of Professional Self-Concept and Job Embeddedness on Nurses' Burnout: Structural Equation Modeling}

\section{Soghra Goliroshan ${ }^{1}$, Monir Nobahar*2,3,4, Nayyereh Raeisdana ${ }^{2,4}$, Zahra Ebadinejad ${ }^{1}$ Parvin Aziznejadroshan ${ }^{5,6}$}

1- Student Research Committee, Faculty of Nursing and Midwifery, Semnan University of Medical Sciences, Semnan, Iran.

2- Nursing Care Research Center, Semnan University of Medical Sciences, Semnan, Iran

3- Social Determinants of Health Research Center, Semnan University of Medical Sciences, Semnan, Iran

4- Faculty of Nursing and Midwifery, Semnan University of Medical Sciences, Semnan, Iran

5- Nursing Care Research Center, Health Research Institute, Babol University of Medical Sciences, Babol, Iran

6- Faculty of Nursing and Midwifery, Babol University of Medical Sciences, Babol, Iran

\section{Corresponding Author}

Monir Nobahar*(BScN, MSc, PhD): Associate professor, Nursing Care Research Center and Social Determinants of Health Research Center, Faculty of Nursing and Midwifery, Semnan University of Medical Sciences, Semnan, Iran

Email: nobahar43@semums.ac.ir 


\section{Abstract}

Background and aim: Job embeddedness and professional self-concept are among the important nursing components, the existence of which help decrease occupational burnout among nurses. This study aimed to determine the protective role of Professional Self-concept and Job embeddedness on nurses'burnout.

Methods: This descriptive, correlational study had a predictive design and was conducted on nurses working in training and healthcare centers of Babol University of Medical Sciences in 2019. In total, 308 nurses were selected by stratified random sampling. In addition, data were collected using demographic characteristics questionnaire, Professional Self-concept questionnaire, Job embeddedness scale and nurses' burnout questionnaire. Moreover, data analysis was performed in SPSS version 19 and LISREL version 8.54 using correlational statistics and structural equation modeling.

Findings: The results showed, there was a significant, negative relationship between Professional Self-concept and nurses' burnout (a regression coefficient of -0.77). Meanwhile, an insignificant negative association was found between Job embeddedness and burnout (a regression coefficient of -0.07). The Job embeddedness and self-concept explained $33 \%$ of the variance in nurses' burnout.

Conclusion: According to the results of the study, Professional Self-concept had an effective role in nurses' burnout. In other words, the higher the Professional Self-concept of nurses, the lower their burnout. Therefore, it is suggested that effective interventional strategies be designed by nursing managers through better planning and a supportive workplace be established to improve Professional Self-concept among nurses and decrease their burnout.

Keywords: Professional Self-concept, Job embeddedness, Burnout, Nurse 


\section{Background}

Burnout was first introduced in clinical psychology research by Freudenberger in 1970 as the syndrome of physical and mental deterioration. This term has three components including emotional exhaustion, depersonalization and lack of accomplishment (1) and Burnout occurs due to imbalance between abilities, skills and available sources with the occupational necessities and demands (2). Burnout is recognized as a problem in all healthcare systems (3). Due to its nature, nursing is a stressful profession that could lead to burnout (4-6), in a way that one out of seven nurses experiences exhaustion and burnout at the end of a working day (7). In addition to its adverse effect on the physical and mental health of the personnel, burnout decreases efficiency, organizational commitment, confidence, citizenship behaviors, creativity, innovation, and the quality of nursing services (8). On the other hand, it can increase hospital costs $(7,9)$, frustration, disappointment, dissatisfaction(10) and result in deviant, destructive behaviors and turnover. It can also lead to aggression towards patients and co-workers and inability to communicate with family and friends (11).

In a study by Hayes et al. (2015) in Australia, 52.5\% of 417 nurses had high emotional exhaustion, whereas $53 \%$ and $58 \%$ of them had a high level of depersonalization and lack of accomplishment, respectively (12). In 2018, Biganeh et al. conducted a research in Shahrud, Iran, demonstrating that $40.7 \%$ of nurses experienced a moderate level of emotional exhaustion while $62.79 \%$ and $68.6 \%$ of them had a low level of depersonalization and lack of accomplishment, respectively (13).

Various studies have been conducted on burnout in Iran and most of them are about its prevalence among nurses or investigate its relationship with a component. Since, extensive research is required in this area to recognize the factors related to the burnout of nurses, and a single study cannot determine all effective variables in this regard(14). It is necessary to conduct further studies on other factors accompanying burnout to take appropriate measures 
in designing programs to prevent or reduce burnout (10). One of the variables addressed in the present study was professional self-concept, because very few studies have been conducted on this concept and none of them investigated its relationship with burnout. However, this study demonstrates that professional self-concept can lead to employees' success in the workplace (15), improvement of individual behaviors and role development (16). Moreover, a positive professional self-concept can play an important role in enhancing adaptation in the stressful nursing environment (17). Cao et al. (2010) showed that a positive understanding of professional self-concept can decrease the stress and burnout experiences in clinical nurses (18). Based on the foregoing issues and considering the effects and complications imposed by burnout on the individual and the organization, the researchers of this study decided to investigate the association between this factor and burnout in nurses.

Professional self-concept means the understanding that nurses have of themselves in the nursing work environment (19). Nurses' self-concept reflects the information and beliefs they have about their role, values, and behaviors, and is an attitude that enhances their sense of professional identity (10). The nurses' professional self-concept is a developing process which starts as soon as the individual is accepted as a nursing student at the university and continues and develops until the time they are allowed to work as a graduate nurse in the clinical context (20). Self-concept is one of the important components in health-related professions, especially nursing. Studies have emphasized the necessity of this issue in the nursing profession $(21,22)$, owing to its considerable role in nurses' abilities to carry out their professional duties. Nurses with higher professional self-concept are more accountable toward their patients and work results and take care of patients with more respect and interest (17). Positive professional self-concept improves nurses' empowerment and clinical performance and problem solving and subsequently enhances the quality of nursing care provided. In contrast, nurses with low professional self-concept have fewer clinical 
competencies, lower occupational satisfaction and a higher intention of turnover (23). In a research by Nwafor et al. (2015) in Nigeria, there was a positive relationship between professional self-concept and occupational satisfaction. On the other hand, a negative association was found between professional self-concept and occupational satisfaction with burnout (10). In 2017, Mosayebi et al. found a negative linear correlation between occupational tension and professional self-concept in Tehran, Iran, in a way that the professional self-concept of nurses increased with the decrease of their occupational tension, and nurses' occupational tension decreased with the increase of their professional selfconcept (17).

Turnover and frequent Nurses displacement between hospital wards are costly problems that healthcare providing organizations face all the time (24). They always look for a solution to keep their nurses (25) because lack of staff or having unskilled personnel decline the quality of the care provided for the patients. Viewing the concept of Job embeddedness can help in this regard, as this concept provides a structure based on the retention of the employees in their organizations and focuses on examining the reasons for which the employees stay in their jobs with regard to organizational factors and the society (26). Since only one study investigated this concept in Iran (27) and considering the fact that the evidence shows Job embeddedness can predict the personnel relocation and the absence from work (28) and burnout is one of the most important factors that leads to leaving the job, the researchers of the present study decided to investigate the association between Job embeddedness and burnout and in fact answer whether Job embeddedness can demonstrate burnout or not? Answering this question can pave the way for healthcare managers to reduce or prevent burnout and retain the medical personnel. According to what was said, Job embeddedness shows a new perspective on organizational behavior that can be established and maintained 
based on the relationships that the employees form with people, organizations and activities inside and outside the organization.

Job embeddedness refers to a collection of forces that connect people to their jobs (29). These forces are shaped inside and outside a job and refer to forces that influence employee retention. In fact, they are indicative of individuals' perceptions of their relationship with aspects of work such as people and groups, person-job fit, and self-sacrifice discussed in turnover (30). The main purpose of Job embeddedness is realizing the reasons for employee retention based on factors related to the organization and society (26). In a research by Reitz et al. (2011) in the United States, there was a strong conceptual relationship between Job embeddedness and employee retention, in a way that Job embeddedness explained $24.6 \%$ of the variance of employee retention (25). In addition, Job embeddedness encompasses three components of links (close work relationship with colleagues), fit between profession and goals and individual values, and sacrifice in career. Together, these components act as a shield against damages and hardships that might be the precursors of turnover (31). In 2018, Hopson et al. in the United States concluded that Job embeddedness includes occupational satisfaction and acts as a method to prevent turnover and increase the retention of nurses and is associated with increased age, social communications and group of peers $(26,27)$. In Hong Kong, $\mathrm{Ng}$ et al. (2009) believed that Job embeddedness had a positive relationship with performance and creativity in the job and a negative association with inefficient behaviors. Different components of Job embeddedness have various effects on job consequences. In this context, embeddedness had a positive effect on the main job performance, communications had a positive effect on creativity, and sacrifice had a positive effect on social behavior (30). Given the fact that burnout is the most important problem of a profession affecting nursing turnover, and since no research has evaluated the role of self-concept and Job embeddedness 
on burnout of nurses, this study aimed to determine the protective role of professional selfconcept and Job embeddedness on nurses' burnout.

\section{Methods}

\section{Design of the Study}

This was a descriptive-correlational study with a predictive design, which was conducted in 2019. The study population consisted of all nurses employed in 4 hospitals (Shahid Beheshti, Shahid yahya nejad, Rouhani and Amirkola) of Babol University of Medical Sciences, Iran. A total of 308 participants were selected by using sample volume formula with confidence interval of $95 \%$. The participants were selected by random sampling. The self-report questionnaires were completed by the nurses. The research instruments were distributed by the researcher in various work shifts and collected after completion.

The inclusion criteria were having a BSc or a higher degree in nursing, a minimum of one year of nursing work experience during the research and willingness to participate in the study. In case any of the participants had a physical or mental illness or did not like to take

part in the study, they were not included in the study from the beginning. Moreover, if a questionnaire was incomplete, it was excluded from the study.

\section{Data collection instruments}

Data were collected using the demographic characteristics questionnaire, Professional Selfconcept questionnaire, Job embeddedness scale, and nurses' burnout questionnaire.

Demographic characteristics included age, gender, level of education, marital status, work experience, employment status, ward, and monthly overtime hours. The professional self- 
concept of nursing instrument is a 36-item tool encompassing six components of self-esteem, communications, knowledge, care, leadership and communication with colleagues. The instrument is scored based on a six-point Likert scale, and the score range of the tools is 36216 (6-36 range of score for each dimension). The questionnaire has been translated into Persian by Badieh Peyma et al. (2013), and Spearman-Brown correlation coefficients and Cronbach's alpha were estimated at 0.89 and 0.97 for validity and reliability of the tool, respectively (32). In addition, the internal consistency of the tools was re-evaluated to assess their reliability, and the Cronbach's alpha was calculated at 0.79 for the present research.

The Job embeddedness scale comprises two subscales of internal (six items) and external (seven items) Job embeddedness. The scale is scored based on a five-point Likert scale, from completely disagree (one score) to completely agree (five scores). In addition, the score range of the scale is 13-65, and its reliability was estimated at the Cronbach's alpha of 0.73 (internal embeddedness) and 0.80 (external embeddedness), respectively (33). In addition, the reliability of the questionnaire was approved at the Cronbach's alpha of 0.80 . On the other hand, the burnout of nurses was assessed by applying the Maslach Burnout Inventory (MBI) (1985). This 22-item tool includes three dimensions of emotional exhaustion, depersonalization and lack of accomplishment, and the items are scored based on a sevenpoint Likert scale (never $=0$ to very high=6). While the dimension of emotional exhaustion has nine items and evaluates being tired of working too much, the dimensions of depersonalization and lack of accomplishment include five and eight items assessing the level of indifference and a sense of depersonalization, and feeling competent and successful at work, respectively. In this tool, the high score of emotional exhaustion and depersonalization or the low score of individual accomplishment demonstrate high levels of burnout. In the emotional exhaustion dimension, the cutoff points of $<16,17-26$, and $\geq 27$ were low, moderate and high, respectively. In the depersonalization dimension, the cutoff points of $<6$, 
$7-12$ and $\geq 13$ were low, moderate and high, respectively. Ultimately, the cutoff points of $\leq 31$, 32-38 and $\geq 39$ were low, moderate and high, respectively, in the lack of accomplishment dimension. Maslach reported a Cronbach's alpha of 71-90\% for the three dimensions, and the tool's reliability was estimated in the range of 60-80 using a re-test (14). In the present study, the reliability of the tool was confirmed at the Cronbach's alpha of 0.786 .

First, nurses who met the inclusion criteria were selected by referring to various hospitals wards following the obtaining of permissions from the ethics committee of Semnan University of Medical Sciences and from the authorities of hospitals in Babol, Iran. After explaining the research objectives to the subjects and ensuring them of the confidentiality terms regarding their personal information, the questions raised by these individuals were answered and written informed consent was obtained prior to the research. In the next stage, the data collection tools were provided to nurses and were collected one week later.

In addition, we adhered to the ethical considerations by obtaining a license from the ethics committee (IR.SEMUMS.REC.1398.041) and the vice-chancellor for research of Semnan University of Medical Sciences, receiving an introduction letter to conduct the study in Babol University of Medical Sciences, explaining the research objectives to the participants and obtaining their consent to participate in the research, ensuring them of the voluntary participation in the study and the confidentiality terms. In addition, we appreciated the cooperation of the subjects and the authorities for their cooperation with the study.

\section{Data analysis}

Data analysis was performed in SPSS version 19 and LISREL 8.54 using descriptive (mean and standard deviation) and inferential (correlation coefficients) statistics. Moreover, the hypothetical structural relations were analyzed by Structural Equation Modeling(SEM) and LISREL software and the final model fit indices were reported. In the structural equation 
modeling, standard coefficients and significance number were used to confirm or reject the research hypothesis (the effect of Professional Self-concept and Job embeddedness on the burnout of clinical nurses) (34). Notably, a P-value of 0.05 was considered statistically significant.

\section{Results}

In this study, the mean age of the participants was $35.59 \pm 7.35$ years. Other Sociodemographic characteristics are mentioned in Table 1.(insert Table1)

According to the results, $45.1 \%$ of 139 individuals suffered from burnout. In other words, the prevalence of burnout in nurses was $45.1 \%$. Regarding the dimensions of burnout, most nurses $(73.7 \%)$ had severe emotional exhaustion, whereas $95.5 \%$ and $67.5 \%$ of them had severe depersonalization and low individual accomplishment, respectively. Moreover, we used mean, standard deviation and correlation matrix between research variables in order to determine the mean variables of the role of self-concept and Job embeddedness in the burnout of nurses and the related subscales (insert Table 2).

Among the dimensions of Professional Self-concept, the mean of communication dimension (4.82) was higher than the moderate level, whereas the mean of leadership (4.23) was lower than the mean of other dimensions. Among the dimensions of Job embeddedness, the mean of internal embeddedness (3.75) was higher than the moderate level. Moreover, the results showed a significant, negative relationship between nurses' burnout and dimensions of selfconcept (care, communication, knowledge, leadership, employee relations, and general selfconcept). On the other hand, no significant association was observed between the correlation coefficient of nurses' burnout and internal and external dimensions of Job embeddedness.

According to Table 1, self-concept had a direct, negative and significant effect on nurses' burnout $(\gamma 11=-.77, \mathrm{t}=-6.44, \mathrm{P} \leq 0.001)$. While the regression coefficient of Job embeddedness 
on burnout of nurses was negative, the coefficient was not significant $(\gamma 21=-.07, t=-0.69$, $\mathrm{P} \geq 0.49$ ). Moreover, the significance coefficients of the model in Figure 2 were indicative of the significance of the model. In this regard, self-concept and Job embeddedness explained $33 \%$ of the variance of nurses' burnout.

According to the results, the communication dimension (factor load $=0.95$ ) in the variable of Professional Self-concept had the highest ability to explain the Professional Self-concept of nurses. In other words, the communication dimension played a more prominent role in the Professional Self-concept of nurses. In addition, among the dimensions of Job embeddedness, the internal and external dimensions of Job embeddedness had the highest (0.89) and lowest (0.81) factor loads, respectively. These results demonstrated that emphasizing the internal Job embeddedness of nurses played the most role in the relationship with this variable. Finally, individual accomplishment dimension in nurses' burnout had the highest factor load (0.71) while the lowest factor load was related to the dimension of emotional exhaustion (0.60).(insert Figure1\&2)

The best index to obtain the model fit is dividing the Chi-square into the degree of freedom. In this regard, the more the score is below three, the better the model fit. In the final model, the score was estimated at 2.98 , which demonstrated the suitable fit of the model. The main fit indexes included Chi square equal to 113.43 and degree of freedom equal to 38 . The other index was the root mean square error of approximation (RMSEA), which is below 0.08 for models that have a good fit. Moreover, the scores in the range of 0.08-0.1 are indicative of reasonable errors for approximation in society and acceptable. However, models with RMSEA $=0.10$ have a poor fit. In the conceptual model of the research, the RMSEA was estimated at 0.080 , which showed a relatively good fit of the model. According to Table 3, the mentioned model had a favorable fit with regard to a high level of normed fit index (NFI), 
comparative fit index (CFI), and incremental fit index (IFI) and low level of RMSEA index. (insert Table 3)

\section{Discussion}

According to the results of the study, the Professional Self-concept had a direct, negative and significant effect on nurses' burnout. In other words, burnout of nurses decreased with an increase in their Professional Self-concept. In this regard, our findings are in line with the results obtained by Coa et al. (2015) in China, who reported that Professional Self-concept was a significant and negative predictor of burnout. These scholars marked that the increase in Professional Self-concept can decrease burnout among nurses (35). In addition, the results of Wang et al. (2019) in China were indicative of a significant, negative association between the Professional Self-concept of nursing students and their educational burnout. Furthermore, their results supported the stress and coping theory, which states that self-concept can affect the stress-related reactions of individuals as a cognitive assessment variable (20). In this context, Mosayebi et al. (2017) found a negative linear correlation between job stress and Professional self-concept of nurses in Tehran, in a way that increase of job stress was associated with decreased Professional Self-concept (17). In South Africa, Khamsia et al. (2017) demonstrated that individual stress predicted burnout and general health status of nurses (36). Our results indicate that there is a significant negative correlation between professional self-concept and burnout, and states that Strategies that increase professional self-concept may reduce burnout in clinical nurses. Strategies such as improving nursing knowledge and skills, the ability to communicate and collaborate, self-confidence and sense of leadership are very important for increasing nurses' self-concept. This finding can light the way for health authorities of the country, especially the nursing organization, to alleviate the 
shortcomings and improve the situation of nurses' community by promoting their professional self-concept.

Another result of the present study was indicative of a negative regression coefficient of Job embeddedness on burnout of nurses, which was not significant. In a research by Candan (2016), a negative and significant relationship was observed between some dimensions of Job embeddedness and burnout of employees in a state university in Turkey, which is not in line with our findings. This lack of consistency might be due to different subjects (university employees in the aforementioned study) and questionnaires used to measure Job embeddedness (33). Although it has been reported in several studies that Job embeddedness is an effective factor in employee retention, the researchers of the present study did not find any study which investigated the association between Job embeddedness and burnout in nurses.

Results obtained by Choi et al. (2015) in South Korea demonstrated the higher explanatory ability of Job embeddedness among the factors predicting turnover (37). Heritage et al. (2016) in Australia reported that Job embeddedness was a unique predictive factor of turnover variance (38). The Job embeddedness comprises the components of occupational satisfaction and organizational commitment and is recognized as a combination of reasons for employee retention (25). However, it should be noted that Job embeddedness is not always a positive feature in employees of an organization (39). Reitz (2014) wrote in the United States that employee retention might occur out of desperation or due to limited employment options while there is negative Job embeddedness (25). Which seems to be in accordance with the current state of our nurses' community to a great extent. Because given the economic conditions of the society and the lack of job opportunities, the workforce is compelled to stay in the organization to maintain their monthly income and manage their livelihood. 
According to the results of the present study, the dimension of communications (factor load $=0.95$ ) had the highest predictive ability regarding the role of self-concept in burnout. Therefore, it seems that the communication dimension played a more prominent role in the effect of nurses' self-concept. The research participants also reported this dimension above the moderate level. According to the results obtained by Darban et al. (2016) in Tehran, the implementation of a communication skills training program significantly decreased nurses' burnout (40). In a study by Consiglio (2014) in Italy, a significant, positive relationship was observed between affective disorders and interpersonal conflict, and pessimism (41). In a study by Penberthy et al. (2018) in the United States, improvement of communication skills over time can significantly decrease physicians' burnout (42). Obtaining this result in the present study could be due to inseparability of communication from nursing care and the greater emphasis on learning communicational skills during university years. In addition, in recent years special attention has been paid to holding in-service training courses for nurses with the aim of improving their relationship with the patients. It appears that the combination of these factors had been effective and lead to such result in this study.

According to the results of the current research, the dimension of internal Job embeddedness had the highest factor load (0.89), which confirmed that internal occupational dimension of nurses' Job embeddedness played the most protective role against burnout. In general, the internal dimensions of an occupation refers to forces that generate from inside the job, such as interest in the career's nature, matching the occupation's conditions or inter-professional communications, and connect people to their jobs (43). Results obtained by Hopson et al. confirmed that increase of age, keeping up with the community, and communication with colleagues were among the most important indicators of Job embeddedness (26). According to Candan et al., Job embeddedness includes two intra and extra-organizational components. In this regard, the intra-organizational dimension has a negative correlation with employees' 
burnout while having no association with occupational performance (33). Adams et al. (2010) also showed a relationship between the internal dimension of Job embeddedness and organizational commitment (39). As already mentioned, the interest in the nature of the profession and the inter-professional communication are of great importance in the internal aspect of professional embeddedness. In this regard, the results of the present study reveal the great role of communication. As the number of an employee's communications with the society and the organization grows, the degree of professional embeddedness increases. Since their job necessitates, nurses have various formal and informal relationships with different groups and people. According to the findings of researches, age can be cited as another factor related to the internal aspect of professional embeddedness. It is assumed that elder employees have stronger connections with their organizations and societies and it is less likely that they leave their jobs. This is totally in accordance with the findings of the present study in which the average age of the participant nurses was 35 years.

In MBI, a high total score is indicative of higher burnout. In the present study, the dimension of individual accomplishment had the highest factor load (0.71) among the dimensions of MBI, meaning that the mentioned dimension played the most role in the formation of burnout in nurses and the subjects evaluated received low scores in the accomplishment dimension. Soleimani et al. (2016) reported in Rasht, Iran that nurses in Heshmat Hospital received a high accomplishment score (25.71) whereas nurses in Shafa Hospital obtained a moderate score (34.70) in this regard (5). It seems that the main reasons for lack of accomplishment in the present study stem from negative attitude, lack of interest and lack of satisfaction of nurses with their profession and decreased self-confidence. Weak self-esteem in nurses can stem from the negative public image of the nursing profession, harsh working conditions with low salaries and the poor social identity of this profession. Most nurses are probably not able to prove their competency at the workplace due to lack of positive workplace conditions. 
Moreover, doctor-oriented atmosphere of hospitals conveys this sense to nurses that despite the knowledge and skills they acquired during their education, they should merely implement the doctors' orders (7). Results obtained by Mohammadpour Asl et al. (2012) in Tabriz, Iran were indicative of lack of individual accomplishment mostly due to lack of occupational satisfaction, lack of adequate respect, low participation of employees in decision-makings and lack of distinguishing efficient and non-efficient employees (44). In addition, most participants complained about emotional exhaustion (73.7\%) and depersonalization (95.5), which should alarm executives and officials in this area. In addition to negative effects on the physical and mental health of personnel, burnout decreases service quality while increasing interpersonal conflicts, consecutive delays, and hospital costs (5). Emotional exhaustion occurs in the form of reduced energy and mental power to perform duties, whereas depersonalization emerges as a negative response, heartless behaviors toward colleagues and clients, and perceiving people as non-human objects (7,8). In Birjand, Khazaei et al. (2006) marked that $53.3 \%$ of nurses had mild emotional fatigue while $54.2 \%$ of them had severe depersonalization (11). According to the results obtained by Hayes et al. (2015) in New Zealand, $52.5 \%$ of nurses had severe emotional exhaustion, whereas $53 \%$ of the subjects had severe depersonalization (12).The high level of emotional exhaustion in the present study might be due to the high number of patients, lack of organizational support, high workload in the hospital, lack of extra benefit for the staffs and receiving a fixed salary (not related to the number of the clients) and take care of patients with Complicated physical problems. Moreover, lack of individual success led to depersonalization and lack of a positive human attitude during care provision since nurses failed to recognize their abilities, which resulted in their frustration, lack of motivation, and depersonalization.

\section{Limitations of the study}


One of the limitations of the present study was that it was a cross-sectional study which was not able to identify the causal relationships between the research variables. Therefore, it is suggested that a longitudinal study be conducted in the future to determine the causal relationships between these variables. Moreover, the self-report method may not adequately reflect the mental behaviors and processes and the actual amount of burnout might be greater than what the nurses have reported. As a result, it is recommended to nursing managers and associations to pay more attention to the researches done in this regard and provide a practical solution to this problem. Another limitation of this study was the geographical restriction which means it examined the samples of only one city. It is suggested that further researches be conducted on this subject with larger and more diverse samples and in a wider geographical area. Given the protective role of professional self-concept of nurses in their burnout, it is suggested that measures be taken so that nurses could be able to achieve the self-concept skills since it would help them gain self-knowledge and assess their abilities and strengths against their job demands. This process could act as a buffer even in difficult working conditions. Since burnout is a multidimensional issue and can be affected by various factors, it is recommended that other factors affecting burnout (e.g., work shift system, workload, sleep disorders and psychological diseases) be assessed in future studies.

\section{Conclusion}

According to the results of the present study, $45 \%$ of nurses suffered from burnout. Therefore, designing measures by matrons, such as improving the friendly relations among employees, motivating group work, including employees in decision-makings, giving occupational supports, reducing job conflicts and considering individual differences, could be beneficial in the decrease of burnout. These issues should be considered by nursing managers and authorities at different levels of supervision for the development of physical and mental health of nurses. Nursing managers can also take steps to reduce burnout through strategies 
such as introducing novice nurses to the hospital environment through clinical coaching, employing support groups, enhancing access to professional development and increasing resiliency among nurses. The present study led to the recognition of the protective role of Professional Self-concept in nurses' burnout. Our results also demonstrated that the dimension of communications had the most effect among the dimensions of Professional Self-concept. Since teaching communication skills is a cost-effective and effective method for the decrease of nurses' burnout, it is suggested that proper strategies be used by managers to deal with this issue.

\section{Abbreviations}

MBI: Maslach Burnout Inventory

SEM: Structural Equation Modeling

RMSEA: Root mean square error of approximation

NFI: Normed fit index

CFI: comparative fit index

IFI: Incremental fit index

\section{Declaration}

\section{Ethics approval and consent to participate}

This study was approved by Semnan University of Medical Sciences with the ethical code of IR.SEMUMS.REC.1398.041 on May $21^{\text {st }}, 2019$. Having obtained the required permissions from the university and hospitals authorities, the questionnaires were distributed to study units. Ethical considerations were observed as to principles of information anonymity and 
confidentiality, voluntary participation, obtaining informed written consent, and explaining research goals and procedures to the participants.

\section{Consent for publication}

The article does not contain any individual's details and consent for publication is not applicable.

\section{Availability of data and materials}

The datasets generated and analyzed during the current study are not publicly available due to an agreement with the participants on the confidentiality of the data but are available from the corresponding author on reasonable request.

\section{Competing interests}

The authors have no competing interests to declare.

\section{Funding}

The authors received no financial support for the research, authorship, and/or publication of this article.

\section{Authors' contributions}

All authors (SGR, MN, NRD,ZEN and PAR) have participated in the conception and design of the study. SGR Study conception/design, contributed the data collection, carried out the analysis, interpretation of the data and drafting the manuscript. MN Study conception/design, data collection/ analysis, drafting of manuscript, critical revisions for important intellectual content, supervision, Administrative/technical/material support, Final revision. NR critically 
revised and checked closely the proposal, the analysis and interpretation of the data and design the article. ZEN carried out the analysis, interpretation of the data and drafting the manuscript, PAR has been involved in revising the manuscript critically. All authors read and approved the final manuscript.

\section{Acknowledgments}

we extend our gratitude to the vice-chancellor for research of the Semnan and Babol universities of medical sciences, as well as all nurses in Beheshti, Yahyanejhad, Rouhani, and Amirkala hospitals for assisting us in performing the research.

\section{References}

1. Shakerinia I, Mohammadpour M. Relationship between job stress and resiliency with occupational burnout among nurses. Journal of Kermanshah University of Medical Sciences. 2010;14(2):161-9.

2. Tromp D, Van Rheede A, Blomme RJ. The relationships between psychological strain, organizational support, affective commitment and turnover intentions of highly educated hospitality employees. Advances in Hospitality and Leisure. 2010;6:117-34.

3. Khamisa N, Peltzer K, Ilic D, Oldenburg B. Effect of personal and work stress on burnout, job satisfaction and general health of hospital nurses in South Africa. health sa gesondheid. 2017;22(1):252-8.

4. Jafari E, Heshmati R, Faghani R, Tanghestani M. The predictive role of self-efficacy, resiliency and practice of religious beliefs in job burnout of nurses Journal of Urmia Nursing And Midwifery Faculty. 2018 ;16(3):188-97.

5. Soleimani R, Shokrgozar S, Kianmehr S, Fallahi M, Pakdaman M. Comparison of mental health and burn out in medical staff of Rasht Shafa and Heshmat Hospitals. Research in Medical Education. 2016;7(4):2030.

6. Chou L-P, Li C-Y, Hu SC. Job stress and burnout in hospital employees: comparisons of different medical professions in a regional hospital in Taiwan. BMJ open. 2014;4(2):e004185.

7. Klein J, Grosse Frie K, Blum K, von dem Knesebeck O. Burnout and perceived quality of care among German clinicians in surgery. International Journal for Quality in Health Care. 2010;22(6):525-30. 
8. Hashemi T, Golparvar M. The role of perceived organizational support on relationship between job stress and emotional exhaustion with turnover among nurses. Journal of clinical nursing and midwifery. 2016 ;4(4):29-39.

9. Golparvar M, Hosseinzadeh B. Model of relation between person-job none fit with emotional exhaustion and desire to leave work: Evidence for the stress-unequilibrium-compensation model. Journal of Applied Psychology. 2011;5(1):41-56.

10. Nwafor CE, Immanel EU, Obi-Nwosu H. Does nurses'self-concept mediate the relationship between job satisfaction and burnout among Nigerian nurses. International Journal of Africa Nursing Sciences. 2015;3 $: 71-5$.

11. Khazaei I, Khazaee T, Sharifzadeh GR. Nurses'professional Burnout and some Predisposing Factors. Journal of Birjand University of Medical Sciences. 2006; 13(1):56-62.

12. Hayes B, Douglas C, Bonner A. Work environment, job satisfaction, stress and burnout among haemodialysis nurses. Journal of nursing management. 2015;23(5):588-98.

13. Biganeh J, Abolghasemi J, Alimohammadi I, Ebrahimi H, Torabi Z, Ashtarinezhad A. Survey of occupational stress effects on burnout among nurses. journal of knowledge \& Health shahroud university of medical sciences. 2018;13(1):10-8.

14. Maslach C, Jackson SE. The measurement of experienced burnout. Journal of organizational behavior . 1981;2(2):99-113.

15. Golestan F, Ashktorab T, Mohtashami J, Salmani F. Professional self-concept in Nurses working in intensive cares unit in hospitals affiliated to medical sciences universities of Tehran in 2014. Advances in nursing \& midwifery. 2016 Mar 2;25(90):39-46.

16. Heydari A, Shokouhi Targhi E. The effect of an educational-orientation program upon professional self-concept of undergraduate nursing students. Iranian journal of medical education. 2014;14(6):438-94.

17. Mosayebi M, Rassouli M, Nasiri M. Correlation of Occupational Stress with Professional Self-concept in Pediatric Nurses. Journal of Health Promotion Management. 2018;6(6):23-9.

18. Cao X, Lu L, Liu X. The mediating effect of professional self-concept between nurses' professional identification and job burnout. Chinese Journal of Nursing. 2010;45(1):965-8.

19. Cowin LS, Johnson M, Craven RG, Marsh HW. Causal modeling of self-concept, job satisfaction, and retention of nurses. International Journal of Nursing Studies. 2008;45(10):1449-59. 
20. Wang M, Guan H, Li Y, Xing C, Rui B. Academic burnout and professional self-concept of nursing students: A cross-sectional study. Nurse education today. 2019;77:27-31.

21. Seobuk-gu C-S. The relationship between problem solving ability, professional self concept, and critical thinking disposition of nursing students. International journal of Bio-Science and bio-technology. 2014 ;6(5):131-42.

22. Kelly S, Courts N. The professional self-concept of new graduate nurses. Nurse education in practice. 2007;7(5):332-7.

23. Jahromi ZB, Kargar M, Ramezanli S. Study of the relationship between nurse self-concept and clinical performance among nursing students. Jentashapir Journal of Health Research. 2015;6(5):54-8.

24. Yoo MJ, Kim JK. A structural model of hospital nurses' turnover intention: Focusing on organizational characteristics, job satisfaction, and job embeddedness. Journal of Korean academy of nursing administration. 2016;22(3):292-302.

25. Reitz OE, Anderson MA, Hill PD. Job embeddedness and nurse retention. Nursing administration quarterly. 2010;34(3):190-200.

26. Hopson M, Petri L, Kufera J. A new perspective on nursing retention: Job embeddedness in acute care nurses. Journal for nurses in professional development. 2018;34(1):31-7.

27. Khaje $\mathrm{N}$.Indirect impact of openness to experience and job performance of nurses: mediations of proactive personality, occupational embeddedness and subjective occupational success. Quarterly Journal of Nursing Management. 2018;6(3):38-47.

28. Sun T, Zhao XW, Yang LB, Fan LH. The impact of psychological capital on job embeddedness and job performance among nurses: a structural equation approach. Journal of advanced nursing. 2012;68(1):69-79. 29. Feldman DC, Ng TW. Careers: Mobility, embeddedness, and success. Journal of management. 2007;33(3):350-77.

30. Ng TW, Feldman DC. Occupational embeddedness and job performance. Journal of Organizational Behavior: The International Journal of Industrial, Occupational and Organizational Psychology and Behavior. 2009;30(7):863-91.

31. Adams GA, Webster JR, Buyarski DM. Development of an occupational embeddedness measure. Career Development International. 2010. 
32. Badiyepeymaye Jahromi Z, Keshavarzi S, Jahanbin I. Determination of the reliability and validity of the Persian version of nurses' self-concept questionnaire (NSCQ). Journal of Nursing Education. 2014;2(4):6371.

33. Candan H. A research on the relationship between job embeddedness with performance and burnout of academicians in Turkey. IOSR Journal of Business and Management. 2016;18(3):68-80.

34. Mueller RO. Basic principles of structural equation modeling: An introduction to LISREL and EQS: Springer Science \& Business Media; 1999.

35. Cao X, Chen L, Tian L, Diao Y, Hu X. Effect of professional self-concept on burnout among community health nurses in $\mathrm{C}$ hengdu, $\mathrm{C}$ hina: the mediator role of organisational commitment. Journal of clinical nursing. 2015;24(19-20):2907-15.

36. Khamisa N, Oldenburg B, Peltzer K, Ilic D. Work related stress, burnout, job satisfaction and general health of nurses. International journal of environmental research and public health. 2015;12(1):652-66.

37. Choi JS, Kim KM. Job embeddedness factors as a predictor of turnover intention among infection control nurses in Korea. American journal of infection control. 2015;43(11):1213-7.

38. Heritage B, Gilbert JM, Roberts LD. Job embeddedness demonstrates incremental validity when predicting turnover intentions for Australian university employees. Front Psychol. 2016;7:582.

39. Adams G.A WJR, Buyarski D.M. Development of an occupational embeddedness measure Career Development International 2010;15(5):420-36.

40. Darban F, Balouchi A, Narouipour A, Safarzaei E, Shahdadi H. Effect of communication skills training on the burnout of nurses: a cross-sectional study. Journal of clinical and diagnostic research: JCDR. 2016;10(4):1-4.

41. Consiglio C. Interpersonal strain at work: A new burnout facet relevant for the health of hospital staff. Burnout Research. 2014;1(2):69-75.

42. Penberthy JK, Chhabra D ,Ducar DM, Avitabile N, Lynch M, Khanna S, et al. Impact of Coping and Communication Skills Program on Physician Burnout, Quality of Life, and Emotional Flooding. Saf Health Work. 2018;9(4):381-7.

43. Reitz OE, Anderson MA. An overview of job embeddedness .Journal of professional nursing : official journal of the American Association of Colleges of Nursing. 2011;27(5):320-7.

44. Mohammadpoorasl A, Maleki A, Sahebihagh MH. Prevalence of professional burnout and its related factors among nurses in Tabriz in 2010 .Iranian journal of nursing and midwifery research. 2012;17(7):524-9. 


\section{Figures}

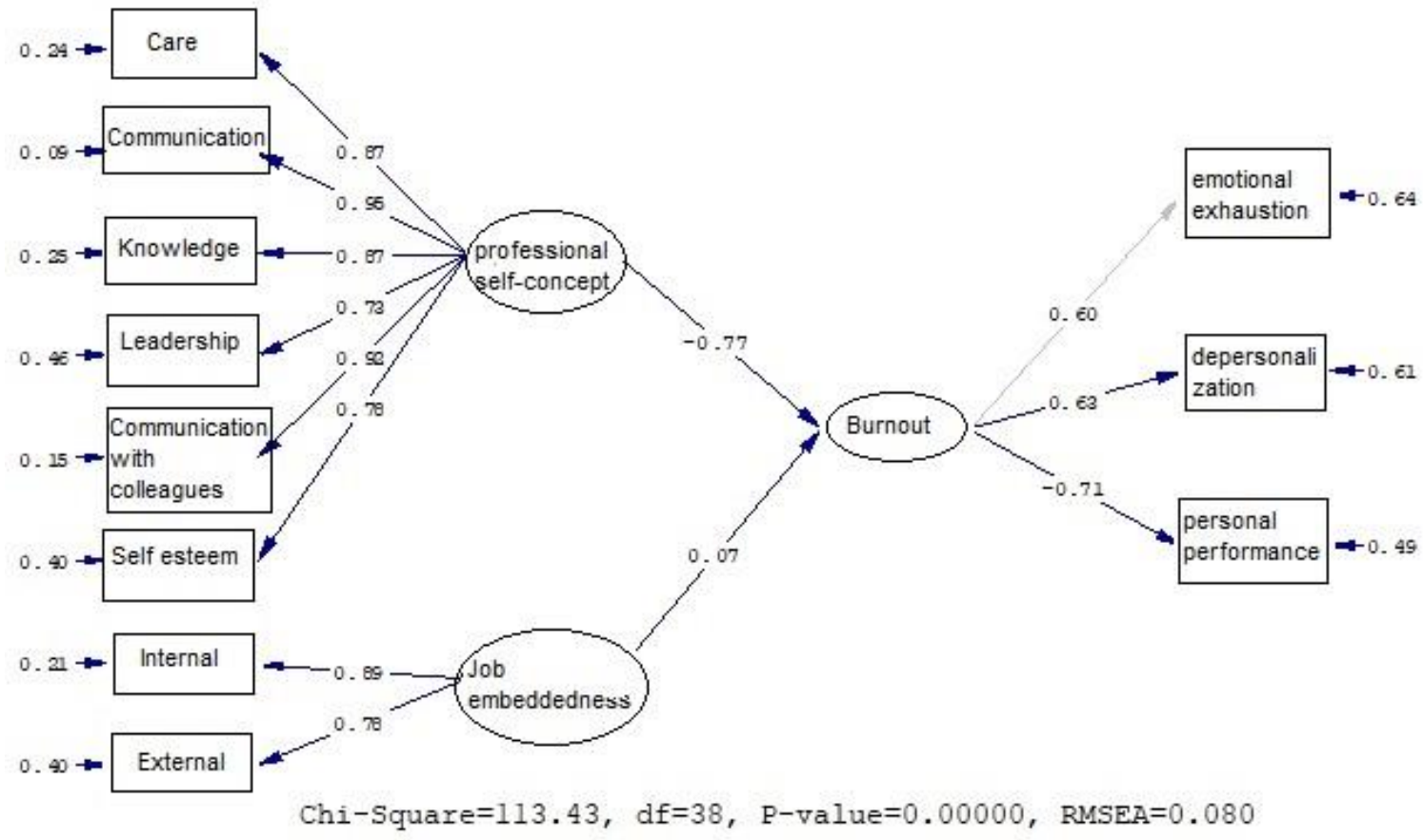

Figure 1. The final model of the role of Professional Self-concept and Job embeddedness in nurses' burnout

*Standard coefficients are reported 


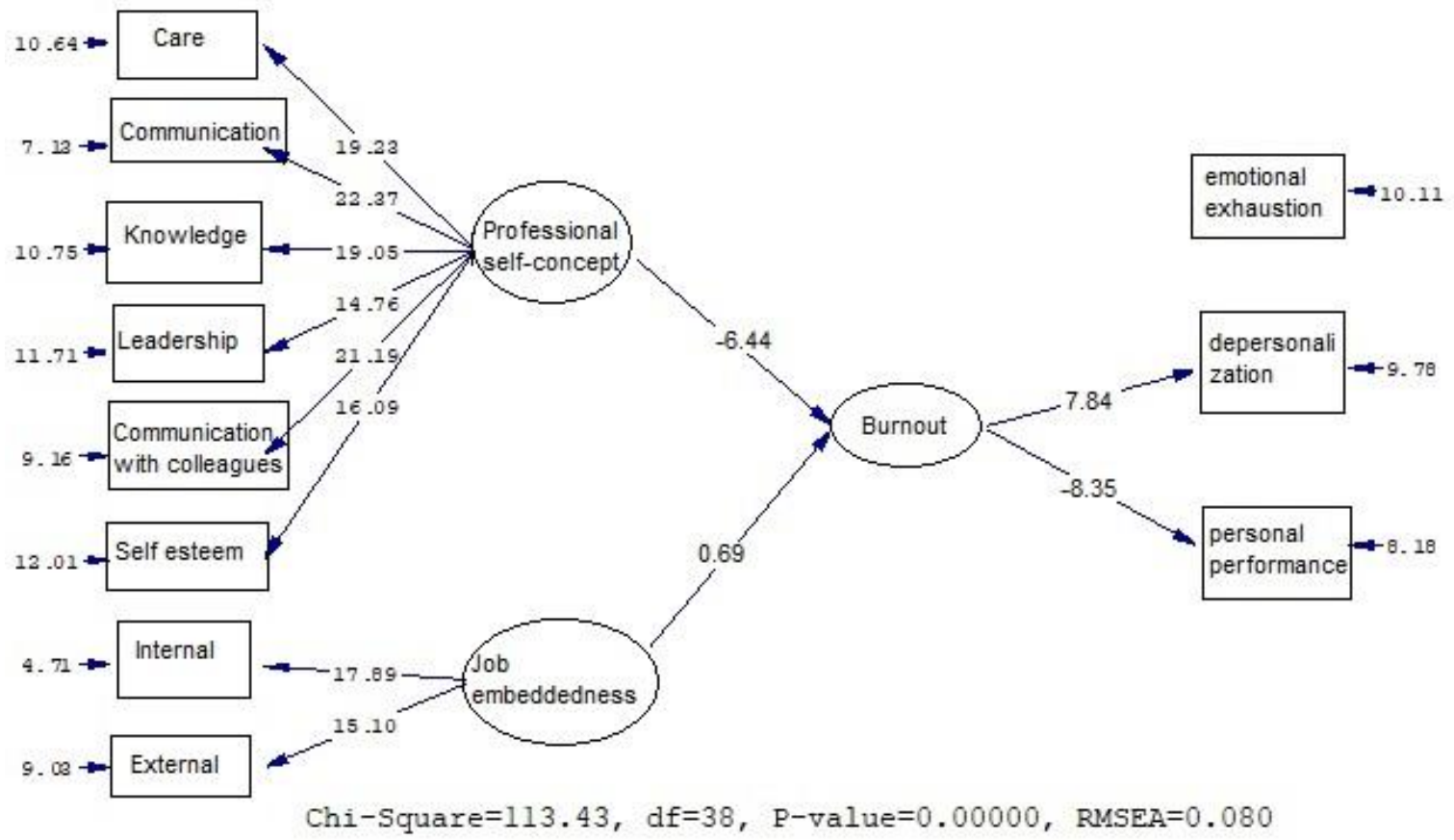

Figure 2. The final model of the role of Professional Self-concept and Job embeddedness in nurses' burnout

*Significant coefficients are reported 


\section{Tables}

\begin{tabular}{|c|c|c|c|}
\hline \multicolumn{2}{|c|}{ Variable } & $\mathbf{N}(308)$ & $\%$ \\
\hline Gender & $\begin{array}{l}\text { Female } \\
\text { Male }\end{array}$ & $\begin{array}{c}244 \\
64\end{array}$ & $\begin{array}{l}79 \% \\
21 \%\end{array}$ \\
\hline Marital status & $\begin{array}{c}\text { Single } \\
\text { Married } \\
\text { Widow or divorced }\end{array}$ & $\begin{array}{c}51 \\
256 \\
1\end{array}$ & $\begin{array}{c}16 / 6 \% \\
83 / 1 \% \\
0 / 3 \%\end{array}$ \\
\hline Level of education & $\begin{array}{c}\text { Bachelors degree } \\
\text { Master degree }\end{array}$ & $\begin{array}{c}273 \\
35\end{array}$ & $\begin{array}{l}88 / 6 \% \\
11 / 4 \%\end{array}$ \\
\hline Type of ward & $\begin{array}{c}\text { General } \\
\text { Critical care }\end{array}$ & $\begin{array}{l}189 \\
119 \\
\end{array}$ & $\begin{array}{l}61 / 4 \% \\
38 / 6 \% \\
\end{array}$ \\
\hline Shift schedule & $\begin{array}{l}\text { Morning shift } \\
\text { Circulating }\end{array}$ & $\begin{array}{c}24 \\
284 \\
\end{array}$ & $\begin{array}{c}7 / 8 \% \\
92 / 2 \%\end{array}$ \\
\hline Work experience & $\begin{array}{c}<5 \\
6-10 \\
11-15 \\
16-20 \\
21-25 \\
26-30 \\
\end{array}$ & $\begin{array}{l}59 \\
79 \\
99 \\
39 \\
17 \\
15 \\
\end{array}$ & $\begin{array}{c}19 / 2 \% \\
25 / 6 \% \\
32 / 1 \% \\
12 / 7 \% \\
5 / 5 \% \\
4 / 9 \%\end{array}$ \\
\hline Monthly overtime hours & $\begin{array}{c}<50 \\
50-100 \\
100-150 \\
>150\end{array}$ & $\begin{array}{c}43 \\
169 \\
83 \\
13\end{array}$ & $\begin{array}{c}14 \% \\
54 / 9 \% \\
26 / 9 \% \\
4 / 2 \%\end{array}$ \\
\hline Employment status & $\begin{array}{c}\text { Formal } \\
\text { By Contract } \\
\text { Compulsory service } \\
\text { course }\end{array}$ & $\begin{array}{c}226 \\
43 \\
39\end{array}$ & $\begin{array}{c}73 / 3 \% \\
14 \% \\
12 / 7 \%\end{array}$ \\
\hline
\end{tabular}


Table 2. Results of correlation coefficient of research variables

\begin{tabular}{|c|c|c|c|c|c|c|c|c|c|c|c|}
\hline Variable & Mean & $\begin{array}{l}\text { Standard } \\
\text { deviation }\end{array}$ & (1) & (2) & (3) & (4) & (5) & (6) & (7) & (8) & (9) \\
\hline 1. $\quad$ Care & 4.68 & $0 \pm 0.70$ & - & & & & & & & & \\
\hline 2. $\quad$ communications & 4.82 & $0 \pm 0.72$ & $0.830^{\text {** }}$ & - & & & & & & & \\
\hline 3. $\quad$ Knowledge & 4.54 & $0 \pm 0.81$ & $0.787 * *$ & $0.821 * *$ & - & & & & & & \\
\hline 4. Leadership & 4.23 & $0 \pm 0.78$ & $0.702 * *$ & $0.705^{* *}$ & $0.637 * *$ & - & & & & & \\
\hline $\begin{array}{l}\text { 5.communication with } \\
\text { colleagues }\end{array}$ & 4.74 & $0 \pm 0.69$ & $0.788 * *$ & $0.893^{* *}$ & $0.776^{* *}$ & $0.680^{* *}$ & - & & & & \\
\hline 6. self-esteem & 4.32 & $0 \pm 0.99$ & $0.617 * *$ & $0.712 * *$ & $0.801^{* *}$ & $0.528^{* *}$ & 0.696 *** & - & & & \\
\hline $\begin{array}{l}\text { 7. Internal } \\
\text { embeddedness }\end{array}$ & 3.75 & $0 \pm 0.69$ & $0.583^{* *}$ & $0.606^{* *}$ & $0.665^{* *}$ & $0.445^{* *}$ & $0.585^{* *}$ & $0.784 * *$ & - & & \\
\hline $\begin{array}{l}\text { 8. External } \\
\text { embeddedness }\end{array}$ & 3.33 & $0 \pm 0.75$ & $0.535^{* *}$ & $0.534 * *$ & $0.580^{* *}$ & $0.429 * *$ & $0.545^{* *}$ & $0.597 * *$ & $0.376^{* *}$ & - & \\
\hline 9. Burnout & 3.91 & $0 \pm 0.84$ & -0.493 & $-0.522 * *$ & $-0.559 * *$ & $-0.394 * *$ & $-0.547 * *$ & $-0.548 * *$ & -0.112 & -0.143 & - \\
\hline
\end{tabular}


Table 3. Fit indexes of the final model

\begin{tabular}{|c|c|c|c|c|}
\hline Index & Source & Acceptable range & Value & Result \\
\hline $\mathrm{X}^{2}$ & Mueller (1996) & $\mathrm{P}>0.05$ & 113.43 & Confirmed \\
\hline Df & - & - & 38 & - \\
\hline $\mathrm{X}^{2} / \mathrm{df}$ & Bollen (1989) & $<3$ & 2.98 & Confirmed \\
\hline RMSEA & MacCallum (1996) & RMSEA $<0.08$ & 0.080 & Confirmed \\
\hline GFI & Bagozzi \& Yi (1988) & $\mathrm{GFI}>0.80$ & 0.93 & Confirmed \\
\hline AGFI & Bagozzi \& Yi (1988) & AGFI $>0.80$ & 0.88 & Confirmed \\
\hline NFI & Fornell \& Larcker (1981) & NFI $>0.90$ & 0.98 & Confirmed \\
\hline CFI & Hu \& Bentler (1999) & CFI $>0.90$ & 0.98 & Confirmed \\
\hline IFI & Shah \& Ward (2007) & IFI $>0.90$ & 0.98 & Confirmed \\
\hline
\end{tabular}


Figures

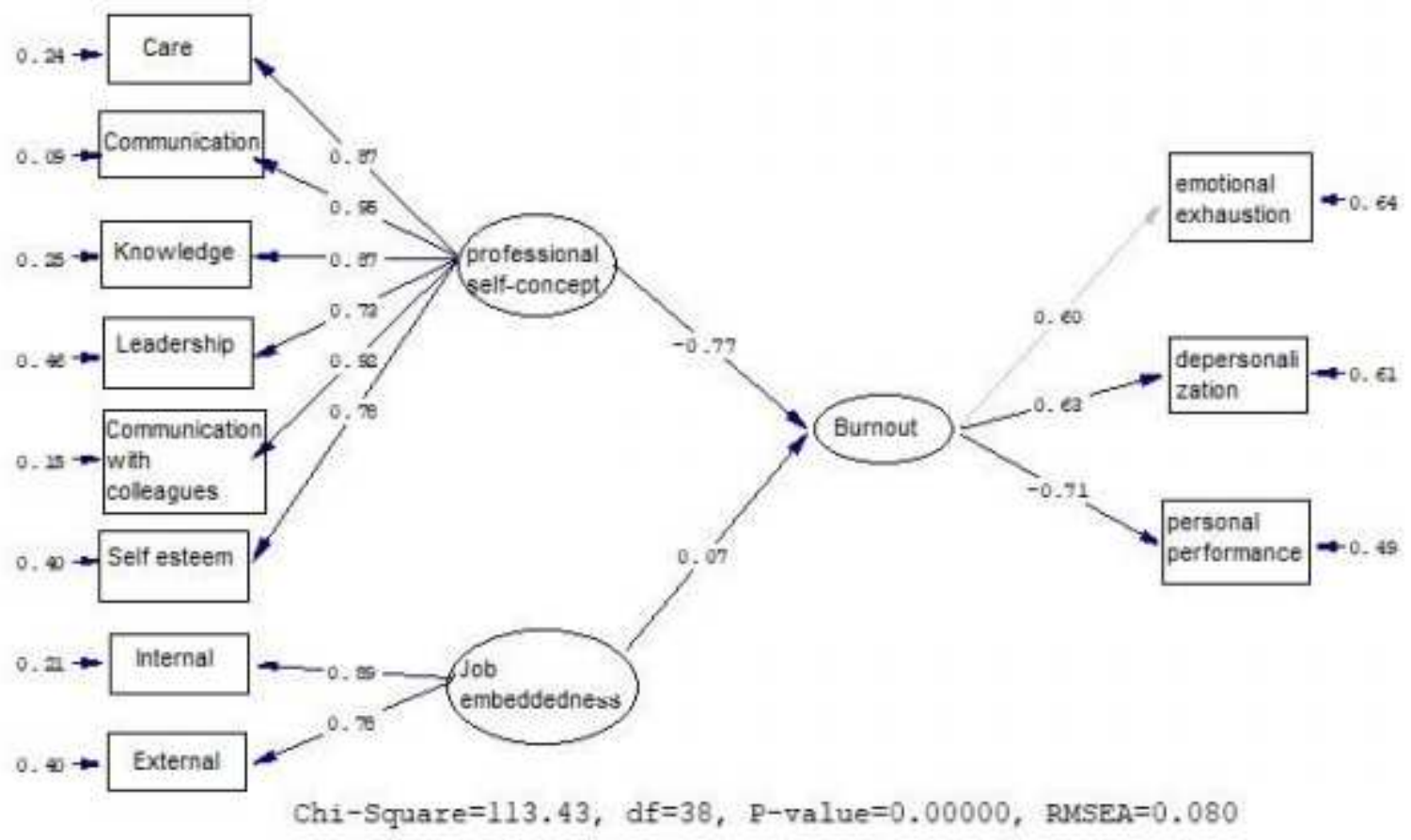

Figure 1

The final model of the role of Professional Self-concept and Job embeddedness in nurses' burnout *Standard coefficients are reported

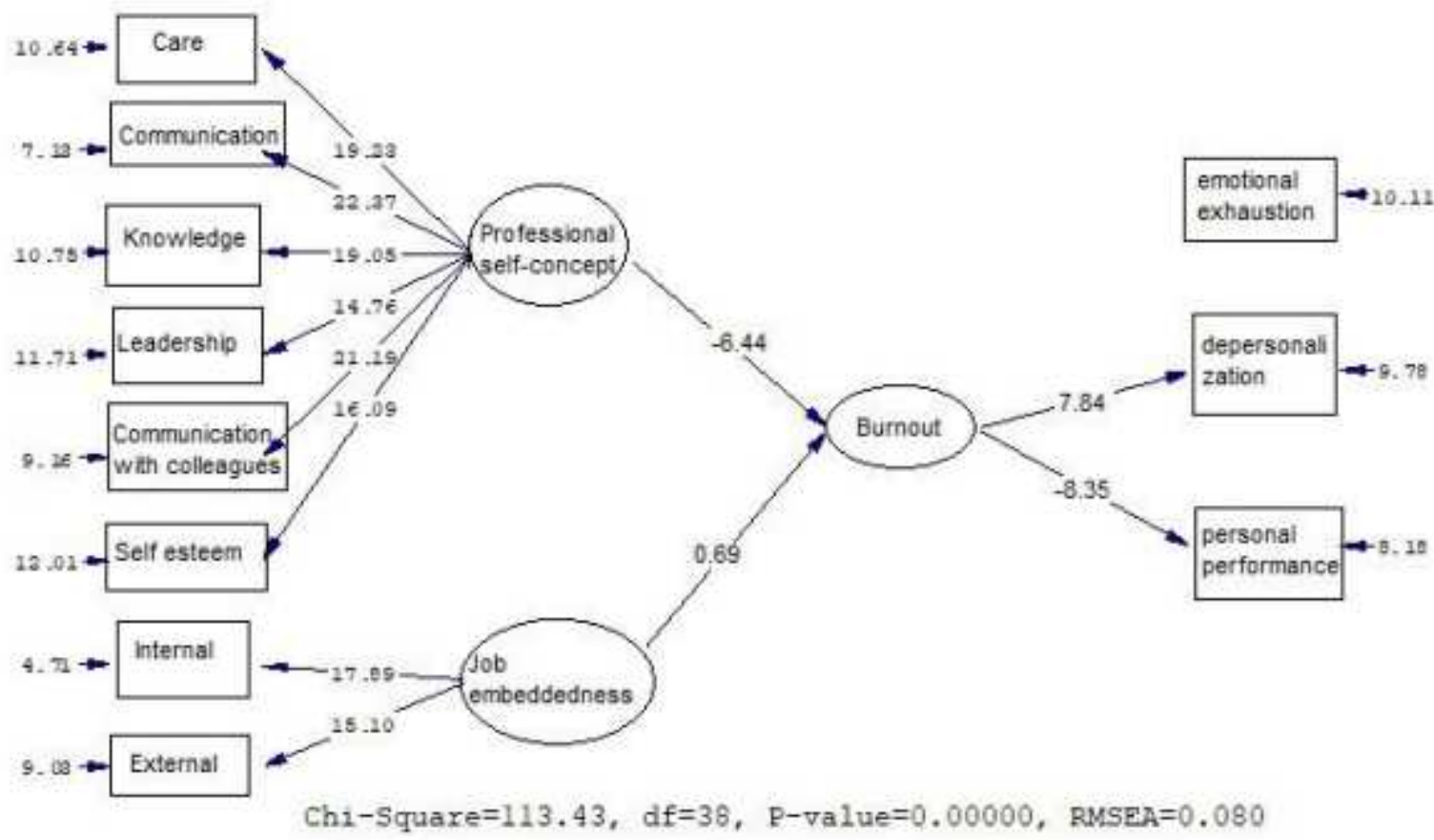

Figure 2 
The final model of the role of Professional Self-concept and Job embeddedness in nurses' burnout *Significant coefficients are reported 